\title{
A Study of Derivatives
}

\author{
R Savithri $^{1}$, B Saidulu ${ }^{2}$ \\ ${ }^{I}$ (Mba, Kottam College/ JNTU University, INDIA) \\ ${ }_{2}^{2}(M B A$, Ronald Ross P.G College/ Osmania University, INDIA)
}

\begin{abstract}
Derivatives, ranging from relatively simple forward contracts to complicated options products, are an increasingly important feature of financial markets worldwide. They are already being used in many emerging markets, and as the financial sector becomes deeper and more stable, their use is certain to grow. This Handbook provides a basic guide to the different types of derivatives traded; the derivatives markets all over the world have shown tremendous growth in recent years.
\end{abstract}

Keywords: Arbitrageurs, Baskets, Hedgers, , LEAPS , Strike Price

\section{Introduction}

A derivative security is a security whose value depends on the value of together more basic underlying variable. These are also known as contingent claims. Derivatives securities have been very successful in innovation in capital markets. The emergence of the market for derivative products most notably forwards,futures and options can be traced back to the willingness of risk -averse economic agents to guard themselves against uncertainties arising out of fluctuations in asset prices. By their very nature, financial markets are markets by a very high degree of volatility. Through the use of derivative products, it is possible to partially or fully transfer price risks by locking - in asset prices. As instruments of risk management these generally don't influence the fluctuations in the underlying asset prices. However, by locking-in asset prices, derivative products minimize the impact of fluctuations in asset prices on the profitability and cash-flow situation of risk-averse investor. Derivatives are risk management instruments which derives their value from an underlying asset. Underlying asset can be Bullion, Index, Share, Currency, Bonds, Interest, etc

\section{Derivatives}

The emergence of the market for derivative products, most notably forwards, futures and options, can be traced back to the willingness of risk-averse economic agents to guard themselves against uncertainties arising out of fluctuations in asset prices. By their very nature, the financial markets are marked by a very high degree of volatility. Through the use of derivative products, it is possible to partially or fully transfer price risks by locking -in asset prices. As instruments of risk management, these generally do not influence the fluctuations underlying prices. However, by locking -in asset prices, derivative products minimizes the impact of fluctuations in asset prices on the profitability and cash flow situation of risk-averse investors.

\subsection{Securities Contracts}

Understanding the word itself, Derivatives is a key to mastery of the topic. The word originates in mathematics and refers to a variable, which has been derived from another variable. For example, a measure of weight in pound could be derived from a measure of weight in kilograms by multiplying by two. In financial sense, these are contracts that derive their value from some underlying asset. Without the underlying product and market it would have no independent existence. Underlying asset can be a Stock, Bond, Currency, Index or a Commodity.

\subsection{Importance Of Derivatives}

Derivatives are becoming increasingly important in world markets as a tool for risk management. Derivatives instruments can be used to minimize risk. Derivatives are used to separate risks and transfer them to parties willing to bear these risks. The kind of hedging that can be obtained by using derivatives is cheaper and more convenient than what could be obtained by using cash instruments. It is so because, when we use derivatives for hedging, actual delivery of the underlying asset is not at all essential for settlement purposes. Moreover, derivatives would not create any risk. They simply manipulate the risks and transfer to those who are willing to bear these risks.

For example, Mr. A owns a bike If he does not take insurance, he runs a big risk. Suppose he buys insurance [a derivative instrument on the bike] he reduces his risk. Thus, having an insurance policy reduces the risk of owing a bike. Similarly, hedging through derivatives reduces the risk of owing a specified asset, which may be a share, currency, etc. 


\subsection{Characteristics Of Derivatives}

Their value is derived from an underlying instrument such as stock index, currency, etc.

\subsubsection{Risks Involved In Derivatives:}

Derivatives are used to separate risks from traditional instruments and transfer these risks to parties willing to bear these risks. The fundamental risks involved in derivative business includes

A. Credit Risk: This is the risk of failure of a counterpart to perform its obligationas per the contract. Also known as default or counterparty risk, it differs with different instruments.

B. Market Risk: Market risk is a risk of financial loss as a result of adverse movements of prices of the underlying asset/instrument.

C. Liquidity Risk: The inability of a firm to arrange a transaction at prevailing market prices is termed as liquidity risk.

A firm faces two types of liquidity risks:

1) Related to liquidity of separate products.

2) Related to the funding of activities of the firm including derivatives.

D. Legal Risk: Derivatives cut across judicial boundaries, therefore the legal aspects associated with the deal should be looked into carefully.

\section{Major Players In Derivative Market}

There are three major players in the derivatives trading.

1. Hedgers

2. Speculators

3. Arbitrageurs

Hedgers: The party, which manages the risk, is known as "Hedger". Hedgers seek to protect themselves against price changes in a commodity in which they have an interest.

Speculators: They are traders with a view and objective of making profits. They are willing to take risks and they bet upon whether the markets would go up or come down.

Arbitrageurs: Risk less profit making is the prime goal of arbitrageurs. They could be making money even with out putting their own money in, and such opportunities often come up in the market but last for very short time frames. They are specialized in making purchases and sales in different markets at the same time and profits by the difference in prices between the two centers.

\section{Types of Derivatives}

Most commonly used derivative contracts are

\subsection{Forward}

A forward contract is a customized contract between two entities where settlement takes place on a specific date in the futures at today's pre-agreed price. Forward contracts offer tremendous flexibility to the party's to design the contract in terms of the price, quantity, quality, delivery, time and place. Liquidity and default risk are very high.

Forwards are the simplest and basic form of derivative contracts. These are instruments are basically used by traders/investors in order to hedge their future risks. It is an agreement to buy/sell an asset at certain in future for a certain price. They are private agreements mainly between the financial institutions or between the financial institutions and corporate clients. One of the parties in a forward contract assumes a long position i.e. agrees to buy the underlying asset on a specified future date at a specified future price. The other party assumes short position i.e. agrees to sell the asset on the same date at the same price. This specified price referred to as the delivery price. This delivery price is choosen so that the value of the forward contract is equal to zero for both the parties. In other words, it costs nothing to the either party to hold the long/short position.

\subsubsection{Essential Features Of Forward Contracts}

- A forward contract is a Bi-party contract, to be performed in the future, with the terms decided today

- Forward contracts offer tremendous flexibility to the parties to design the contract in terms of the price, quantity, quality, delivery time and place

- Forward contracts suffer from poor liquidity and default risk

- Contract price is generally not available in public domain

- On the expiration date the contract will settle by delivery of the asset 
- If the party wishes to reverse the contract, it is compulsorily to go to the same counter party, which often results high prices

\subsubsection{Forward Trading In Securities}

The Securities Contract (amendment) Act of 1999 has allowed the trading in derivative products in India. As a further step to widen and deepen the securities market the government has notified that with effect from March 1st 2000 the ban on forward trading in shares and securities is lifted to facilitate trading in forwards and futures. It may be recalled that the ban on forward trading in securities was imposed in 1986 to curb certain unhealthy trade practices and trends in the securities market. During the past few years, thanks to the economic and financial reforms, there have been many healthy developments in the securities markets.

\subsection{Future}

A futures contract is an agreement between two parties to buy or sell an asset at a certain time in the future at a certain price. Futures contracts are special types of forward contracts in the sense, that the former are standardized exchange traded contracts. The future contract is an agreement between two parties to buy or sell an asset at a certain specified time in future for certain specified price.

\subsubsection{Features Of Futures Contracts}

Organized Exchanges: Unlike forward contracts which are traded in an over- the- counter market, futures are traded on organized exchanges with a designated physical location where trading takes place. This provides a ready, liquid market which futures can be bought and sold at any time like in a stock market.

Standardization: In the case of forward contracts the amount of commodities to be delivered and the maturity date are negotiated between the buyer and seller and can be Tailor made to buyer's requirement. In a futures contract both these are standardized by the exchange on which the contract is traded.

Clearing House: The exchange acts a clearing house to all contracts struck on the trading floor. For instance a contract is struck between capital A and B. Upon entering into the records of the exchange, this is immediately replaced by two contracts, one between A and the clearing house and another between B and the clearing house. Actual delivery is rare: In most of the forward contracts, the commodity is actually delivered by the seller and is accepted by the buyer. Forward contracts are entered into for acquiring or disposing of a commodity in the future for a gain at a price known today. In contrast to this, in most futures markets, actual delivery takes place in less than one percent of the contracts traded. Futures are used as a device to hedge against price risk and as a way of betting against price movements rather than a means of physical acquisition of the underlying asset. To achieve this most of the contracts entered into are nullified by the matching contract in the opposite direction before maturity of the first.

Margins: In order to avoid unhealthy competition among clearing members in reducing margins to attract customers, a mandatory minimum margins are obtained by the members from the customers. Such a stop insures the market against serious liquidity crisis arising out of possible defaults by the clearing members. The members collect margins from their clients as may be stipulated by the stock exchanges from time to time and pass the margins to the clearing house on the net basis i.e. at a stipulated percentage of the net purchase and sale position.

The margin for future contracts has two components:

Initial margin: In futures contract both the buyer and seller are required to perform the contract. Accordingly, both the buyers and the sellers are required to put in the initial margins. The initial margin is also known as the "performance margin" and usually $5 \%$ to $15 \%$ of the purchase price of the contract.

Marking-to-Market: Marking to market means, debiting or crediting the client's equity accounts with the losses/profits of the day, based on which margins are sought. It is important to note that through marking to market process, the clearinghouse substitutes each existing futures contract with a new contract that has the settlement price or the base price. Base price shall be the previous day's closing Nifty value. .

\subsubsection{Payoff For Futures Contracts}

Futures contracts have linear payoffs. In simple words, it means that the losses as well as profits the buyer and the seller of a futures contract are unlimited. These linear payoffs are fascinating as they can be combined with options and the underlying to generate various complex payoffs.

\subsubsection{Payoff For Buyers Of Futures: Long Futures}

The payoff for a person who buys a futures contract is similar to the payoff for a person who holds an asset. He has a potentially unlimited upside as well as potentially unlimited downside. Take the case of a speculator who buys a two-month Nifty index futures contract when Nifty stands at 4800 . The underlying asset in this case is Nifty portfolio. When the index moves up, the long futures position starts making profits, and when index moves down it starts making losses. 


\subsubsection{Payoff For Seller Of Futures: Short Futures}

The payoff for a person who sells a futures contract is similar to the payoff for a person who shorts an asset. He has potentially unlimited upside as well as potentially unlimited downside.

\subsubsection{Pricing Futures}

Cost of Carry Model: We use fair value calculation of futures to decide the no arbitrage limits on the price of the futures contract. This is the basis for the cost-of-carry model where the price of the contract is defined as follows.

$\mathrm{F}=\mathrm{S}+\mathrm{C}$

Where

F - Futures ,S - Spot price, C - Holding cost or Carry cost ,

This can also be expressed as

$\mathrm{F}=\mathrm{S}(1+\mathrm{r}) \mathrm{T}$

Where $\mathrm{r}$ - Cost of financing, $\mathrm{T}$ - Time till expiration

4.2.6 Pricing Index Futures Given Expresed Dividend Amount

The pricing of index futures is also based on the cost of carry model where the carrying cost is the cost of financing the purchase of the portfolio underlying the index, minus the present value of the dividends obtained from the stocks in the index portfolio.

Example

Nifty futures trade on NSE as one, two and three month contracts. Money can be borrowed at a rate of $15 \%$ per annum. What will be the price of a new two-month futures contract on Nifty?

1. Let us assume that ACC will be declaring a dividend of Rs.10/- per share after 15 days of purchasing of contract.

2. Current value of Nifty is 1200 and Nifty trade with a multiplier of 200.41

3. Since Nifty is traded in multiples of 200 value of the contract is $200 \times 1200=240000$.

4. If ACC has weight of 7\% in Nifty, its value in Nifty is Rs.16800 i.e. (240000x0.07).

5. If the market price of ACC is Rs.140, then a traded unit of Nifty involves 120 shares of ACC i.e. $(16800 / 140)$.

6. To calculate the futures price we need to reduce the cost of carry to the extent of dividend received is Rs. 1200 i.e. (120x10). The dividend is received 15 days later and hence compounded only for the remainder of 45 days. To calculate the futures price we need to compute the amount of dividend received for unit of Nifty. Hence, we divided the compounded figure by 200 .

7. Thus futures price

$\mathrm{F}=1200(1.15) 60 / 365-(120 \times 10(1.15) 45 / 365) / 200=$ Rs. 1221.80.

4.2.7 Pricing Index Futures Given Expresed Dividend Yield

If the dividend flow through out the year is generally uniform, i.e. if there are few historical cases of clustering of dividends in any particular month, it is useful to calculate the annual dividend yield.

$\mathrm{F}=\mathrm{S}(1+\mathrm{r}-\mathrm{q}) \mathrm{T}$ Where

F- Futures price

$S$ - Spot index value

$\mathrm{r}$ - Cost of financing

q - Expected dividend yield

$\mathrm{T}$ - Holding period

Example

A two-month futures contract trades on the NSE. The cost of financing is $15 \%$ and the dividend yield on Nifty is $2 \%$ annualized. The spot value of Nifty is 1200 . What would be the fair value of the futures contract?

Fair value $=1200(1+0.15-0.02) 60 / 365=$ Rs. 1224.3542

4.2.8 Pricing Stock Futures

A futures contract on a stock gives its owner the right and the obligation to buy or sell the stocks.

Like, index futures, stock futures are also cash settled: There is no delivery of the underlying stock. Pricing stock futures when no dividend is expected The pricing of stock futures is also based on the cost of carry model, where the carrying cost is the cost of financing the purchase of the stock, minus the present value of the dividends obtained from the stock. If no dividends are expected during the life of the contract, pricing futures on that stock is very simple. It simply involves the multiplying the spot price by the cost of carry.

Example

SBI futures trade on NSE as one, two and three month contracts. Money can be borrowed at $15 \%$ per annum. What will be the price of a unit of new two-month futures contract on SBI if no dividends are expected during the period?

1. Assume that the spot price of SBI is Rs.228. 
2. Thus, futures price $\mathrm{F}=228(1.15) 60 / 365=$ Rs.223.30.

4.2.9 Pricing Stock Futures When Dividends Are Expected

When dividends are expected during the life of futures contract, pricing involves reducing the cost of carrying to the extent of the dividends. The net carrying cost is the cost of financing the purchase of the stock, minus the present value of the dividends obtained from the stock.

Example

ACC futures trade on NSE as one, two and three month contracts. What will be the price of a unit of new twomonth futures contract on ACC if dividends are expected during the period?

1. Let us assume that $\mathrm{ACC}$ will be declaring a dividend of Rs.10/- per share after 15 days pf purchasing contract.

2. Assume that the market price of ACC is Rs.140/-

3. To calculate the futures price, we need to reduce the cost of carrying to the extent of dividend received. The amount of dividend received is Rs.10/-. The dividend is received 15 days later and hence, compounded only for the remaining 45 days.

4. Thus, the futures price $F=140(1.15) 60 / 365-10(1.15) 45 / 365=$ Rs. 133.08

\subsection{The Differences Between Forwards And Futurs}

- Forward contact is typically a credit instrument between a bank and its client; in futures delivery is reinforced only by depositing a margin.

- Forwards are tailor-made (the bank sets the maturity date and the amount by responding to its client's needs), futures contracts are standardized.

- Forwards are an OTC instrument, futures trade in organized centralized exchanges supported by centralized clearing houses.

- Thus, settlement and margins are strictly regulated in futures; subject to 'relations' in forwards

- In futures, there is daily mark-to-market, in forwards not (therefore, the payoff structure with futures is slightly different from forwards; you may gain or lose slightly more with futures)

- In futures, the clearing house is the counterparty to all outstanding contracts

\subsection{Options}

Options are two types - Calls and Puts. Calls give the buyer the right but not the obligation to buy a given quantity of the underlying asset at a given price on or before a given future date. Puts give the buyer the right but not the obligation to sell a given quantity of the underlying asset at a given price on or before a given date. An option is a derivative instrument since its value is derived from the underlying asset. It is essentially a right, but not an obligation to buy or sell an asset.

Options can be a call option (right to buy) or a put option (right to sell). An option is valuable if and only if the prices are varying. An option by definition has a fixed period of life, usually three to six months.An option is a wasting asset in the sense that the value of an option diminishes as the date of maturity approaches and on the date of maturity it is equal to zero.

\subsubsection{OPTION DEFINITION}

An option is a derivative i.e. its value is derived from something else. In the case of the stock option its value is based on the underlying stock (equity). In the case of the index option, its value is based on the underlying index

\subsubsection{Options Clearing Corporation}

The Options Clearing Corporation (OCC) is guarantor of all exchange-traded options once an option transaction has been completed. Once a seller has written an option and a buyer has purchased that option, the OCC takes over it. It is the responsibility of the OCC who over sees the obligations to fulfill the exercises. If I want to exercise an ACC November 100-call option, I notify my broker. My broker notifies the OCC, the OCC then randomly selects a brokerage firm, which is short of one ACC stock. That brokerage firm then notifies one of its customers who have written one ACC November 100 call option and exercises it. The brokerage firm customer can be chosen in two ways. He can be chosen at random or FIFO basis.Because, OCC has a certain risk that the seller of the option can't fulfill the contract, strict margin requirement are imposed on sellers. This margin requirements acts as a performance Bond. It assures that OCC will get its money.

\subsubsection{Call Option}

A call option gives the holder the right but not the obligation to buy an asset by a certain date for a certain price. A call option gives the owner the right to buy an asset at a fixed pirce during a particular time period. 4.4.4 The Valve Of A Call Option At Expiration 
If the stock pirce is greater than the excercise price, we say that the call is in the money.

\subsubsection{The Pay Off Of A Call Option At Expiration Is}

If the stock price is greater than the strick price, call option value $=$ stock price - strike price.

If the stock pirce is lesser than the strick price call - option valve $=0$

4.4.6 Pay Off Diagrames A Good Way To Understand The Profits And Losses With A Strategy

A convenient way to envision what happens with option strategies as the value of the underlying asset changes is with the use of a profit and loss diagram, known as a "payoff diagram". A Payoff diagram is a graphical representation of the potential outcomes of a strategy. Results may be depicted at any point in time, although the graph usually depicts the results at expiration of the options involved in the strategy.

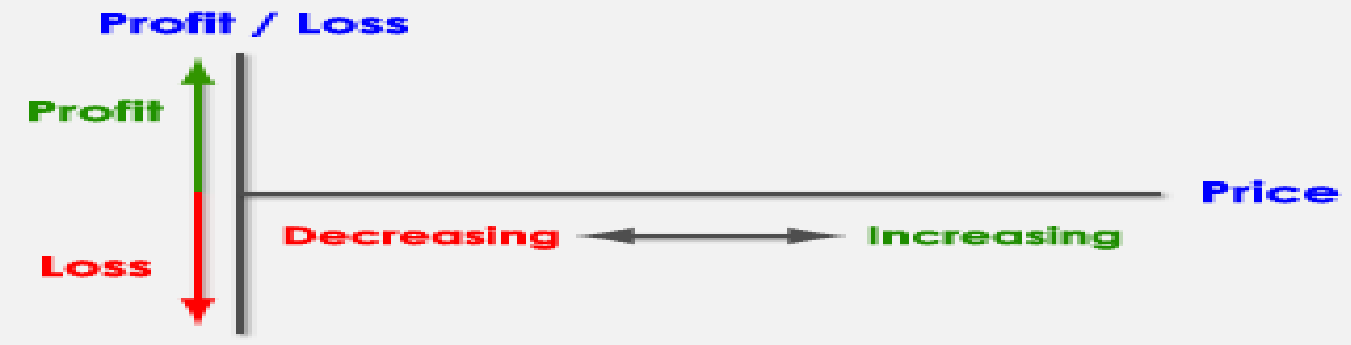

The vertical axis of the diagram reflects profits or losses on option expiration day resulting from particular strategy, while the horizontal axis reflects the underlying asset price on option expiration day. At expiration, there is no time value left, so the option will sell for its intrinsic value. By convention, the diagrams ignore the effect of commissions you have to pay.

"Profit or loss in Baht are graphed on the vertical axis Various underlying asset prices are graphed on the horizontal axis"

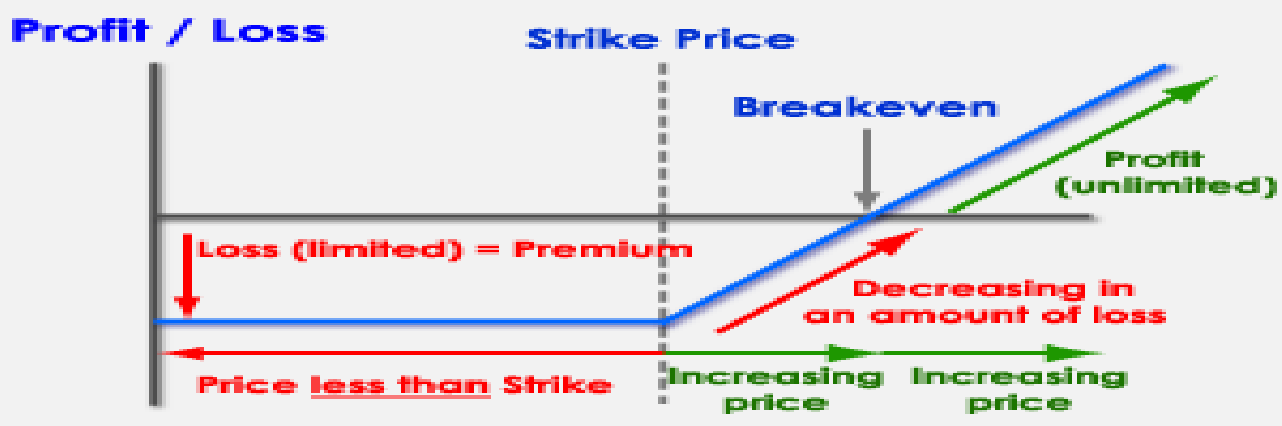

According to the Payoff diagram of Long Call Options strategy, it can be seen that if the underlying asset price is lower then the strike price, the call options holders lose money which is the equivalent of the premium value, but if the underlying asset price is more than the strike price and continually increasing, the holders' loss is decreasing until the underlying asset price reach the breakeven point, and since then the call options holders profit from their long call positions

\subsubsection{More Payoff Examples Of 4 Main Strategies Of Options Investment} Long Call Options

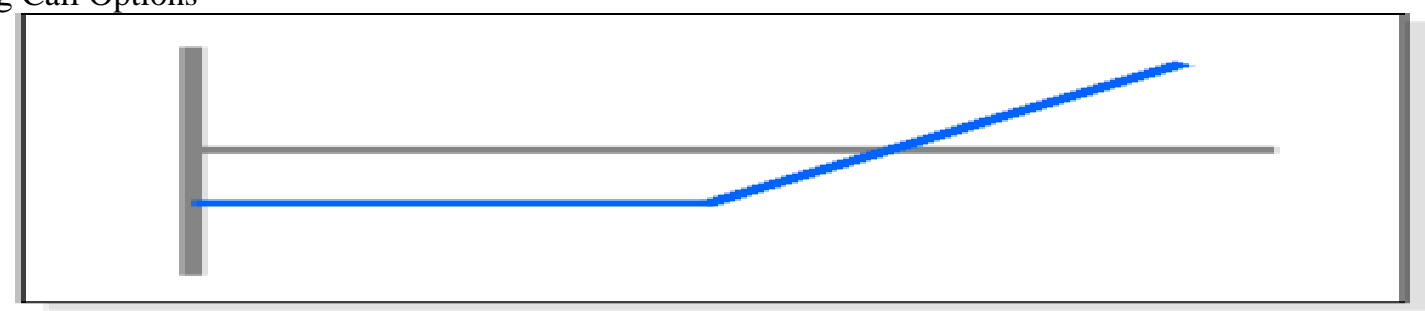

Short Call Options 


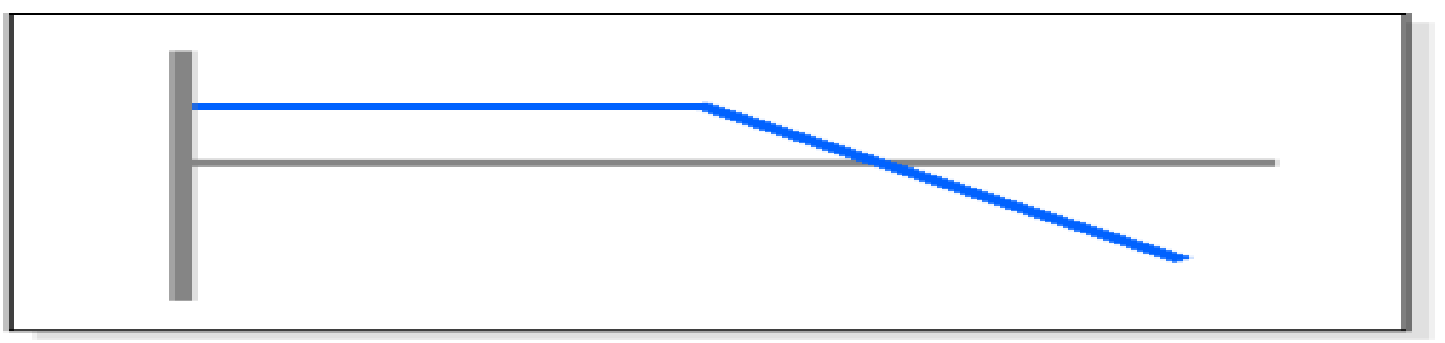

\subsubsection{PUT OPTION} certain price.

A put option gives the holder the right but the not the obligation to sell an asset by a certain date for a Long Put Options

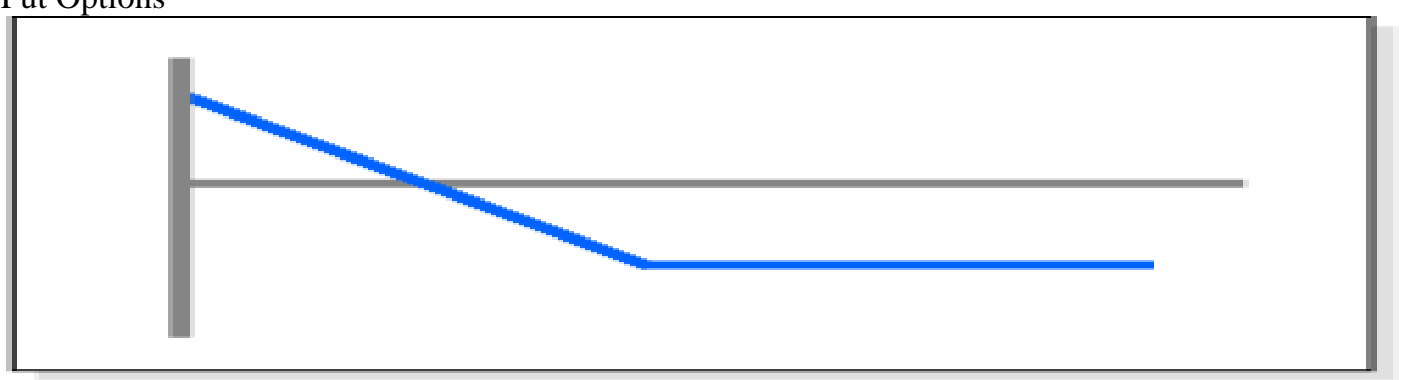

Short Put Options

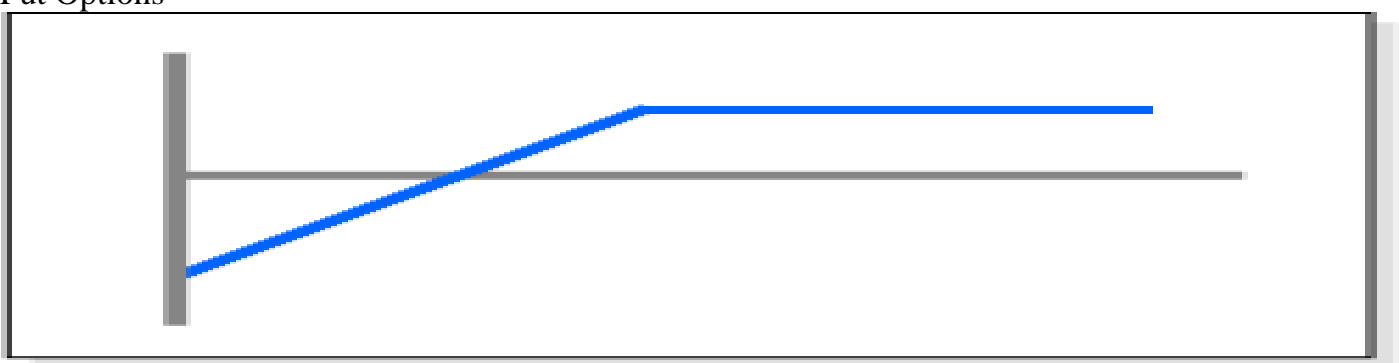

[1] Option price

Option price is the price, which the option buyer pays to the option seller. It is also referred to as the option premium.

[2] Expiration date

The date specified in the option contract is known as the expiration date, the exercise date, the straight date or the maturity date.

[3]Strike Price

The price specified in the option contract is known as the strike price or the exercise price.

[4] American options

American options are the options that the can be exercised at any time up to the expiration date. Most exchangetraded options are American.

[5] European options

European options are the options that can be exercised only on the expiration date itself. European options are easier to analyze than the American options and properties of an American option are frequently deduced from those of its European counterpart.

[6] In-the-money option

An in-the-money option (ITM) is an option that would lead to a positive cash flow to the holder if it were exercised immediately. A call option in the index is said to be in the money when the current index stands at higher level that the strike price (i.e. spot price > strike price). If the index is much higher than the strike price the call is said to be deep in the money. In the case of a put option, the put is in the money if the index is below the strike price.

[7] At-the-money option

An At-the-money option (ATM) is an option that would lead to zero cash flow if it exercised immediately. An option on the index is at the money when the current index equals the strike price (I.e. spot price $=$ strike price).

[8] Out-of-the-money option

An out of the money (OTM) option is an option that would lead to a negative cash flow if it were exercised immediately. A call option on the index is out of the money when the current index stands at a level, which is 
less than the strike price (i.e. spot price < strike price). If the index is much lower than the strike price the call is said to be deep OTM. In the case of a put, the put is OTM if the index is above the strike price.

[9] Intrinsic value of an option

It is one of the components of option premium. The intrinsic value of a call is the amount the option is in the money, if it is in the money. If the call is out of the money, its intrinsic value is Zero. For example $\mathrm{X}$, take that $\mathrm{ABC}$ November-call option.If $\mathrm{ABC}$ is trading at 102 and the call option is priced at 2, the intrinsic value is 2 . If $\mathrm{ABC}$ November-100 put is trading at 97 the intrinsic value of the put option is 3 . If $\mathrm{ABC}$ stock was trading at 99 an $\mathrm{ABC}$ November call would have no intrinsic value and conversely if $\mathrm{ABC}$ stock was trading at 101 an $\mathrm{ABC}$ November-100 put option would have no intrinsic value. An option must be in the money to have intrinsic value.

[10] Time value of an option

The value of an option is the difference between its premium and its intrinsic value. Both calls and puts have time value. An option that is OTM or ATM has only time value. Usually, the maximum time value exists when the option is ATM. The longer the time to expiration, the greater is an options time value. At expiration an option should have no time value.

Characteristics Of Options:

1. Options holders do not receive any dividend or interest.

2. Options holders receive only capital gains.

3. Options holder can enjoy a tax advantage.

4. Options are traded at O.T.C and in all recognized stock exchanges.

5. Options holders can control their rights on the underlying asset.

6. Options create the possibility of gaining a windfall profit.

7. Options holders can enjoy a much wider risk-return combinations.

8. Options can reduce the total portfolio transaction costs.

9. Options enable the investors to gain a better return with a limited amount of investment.

Warrants: Longer - dated options are called warrants and are generally traded over - the - counter. Options generally have life up to one year, the majority of options traded on options exchanges having a maximum maturity of nine months.

LEAPS: The acronym LEAPS means Long Term Equity Anticipation Securities. These are options having a maturity of up to three years.

Baskets: Basket options are options on portfolios of underlying assets. The underlying asset is usually a moving average of a basket of assets. Equity index options are a form of basket options.

Swaps: Swaps are private agreements between two parties to exchange cash flows in the future according to a pre-arranged formula. They can be regarded as portfolios of forward contracts.

The two commonly used swaps are: -

I. Interest rare swaps: These entail swapping only the interest related cash flows between the parties in the same currency. Interest rate swaps, as a name suggest involves an exchange of different payment streams, which are fixed and floating in nature. Such an exchange is referred to as an exchange of borrowings. For example, 'B' to pay the other party 'A' cash flows equal to interest at a pre-determined fixed rate on a notional principal for a number of years. At the same time, party 'A' agrees to pay ' $\mathrm{B}$ ' cash flows equal to interest at a floating rate on the same notional principal for the same period of time. The currencies of the two sets of interest cash flows are the same. The life of the swap can range from two years to fifty years.

II. Currency swaps: These entail swapping both the principal and interest between the parties, with the cash flows in one direction being in a different currency than those in opposite direction.

Currency swaps involves exchanging principal and fixed interest payments on a loan in one currency for principal and fixed interest payments on an approximately equivalent loan in another currency.

A point to note is that the principal must be specified at the outset for each of the currencies. The principal amounts are usually exchanged at the beginning and the end of the life of the swap. They are chosen such that they are equal at the exchange rate at the beginning of the life of the swap.

Like interest swaps, currency swaps are frequently warehoused by financial institutions that carefully monitor their exposure in various currencies so that they can hedge currency risk.

\section{Conclusion}

Derivatives have existed and evolved over a long time, with roots in commodities market. In the recent years advances in financial markets and the technology have made derivatives easy for the investors .Derivatives market in India is growing rapidly unlike equity markets. Trading in derivatives require more than average understanding of finance. Being new to markets maximum number of investors have not yet understood the full implications of the trading in derivatives. 
SEBI should take actions to create awareness in investors about the derivative market. Introduction of derivatives implies better risk management. These markets can give greater depth, stability and liquidity to Indian capital markets. Successful risk management with derivatives requires a thorough understanding of principles that govern the pricing of financial derivatives.In order to increase the derivatives market in India SEBI should revise some of their regulation like contract size, participation of FII in the derivative market.Contract size should be minimized because small investor cannot afford this much of huge premiums.

\section{References}

\section{Books:}

[1]. M.Y. Khan, Indian financial system (Mc Graw Hill Education, 2009).

[2]. V.K. Bhalla, Investment management (S. Chand \&Company Ltd,2012) 